\title{
Cognitive enhancement with methylphenidate and modafinil: conceptual advances and societal implications
}

This article was published in the following Dove Press journal:

Neuroscience and Neuroeconomics

14 August 2015

Number of times this article has been viewed

\author{
Veljko Dubljevićl \\ Christopher James Ryan² \\ 'Department of Neurology and \\ Neurosurgery, McGill University, \\ Montreal, QC, Canada; ${ }^{2}$ Discipline of \\ Psychiatry and the Centre for Values, \\ Ethics and the Law in Medicine, \\ University of Sydney, Sydney, NSW, \\ Australia
}

\begin{abstract}
Cognition enhancement" (CE) drugs are pharmaceuticals taken by healthy people with the aim of sustaining attention, augmenting memory, or improving other cognitive capacities. This paper focuses on two CE drugs - methylphenidate and modafinil. It analyzes their mechanism of action, the evidence for their efficacy in nonsleep deprived individuals, and reviews their adverse effects. It then addresses the normative stances and social issues surrounding CE drug use. Currently, there is little evidence that either methylphenidate or modafinil provide any useful cognitive enhancement to well-rested users. However, it is very possible that future research may reveal cognitive benefits for these agents or for other pharmaceuticals. Public attitudes on CE mirror those evident in academic debate. Even though the majority seem to be opposed to enhancement based on issues of authenticity, utility, and fairness, a steady minority take the view that cognitive enhancer usage is both acceptable and fair. Current legal regimes do not adequately address the social phenomenon of CE use. While the United Nations Convention on Psychotropic Substances defines limits of methylphenidate use across the globe, no such guide exists for modafinil.
\end{abstract}

Keywords: cognitive enhancement, psychopharmacological neuroenhancement, Ritalin, Provigil, neuroethics

\section{Introduction}

"Cognition enhancement" (CE) drugs are pharmaceuticals taken by healthy people with the aim of sustaining attention, augmenting memory, or improving other cognitive capacities. Though the findings of studies into prevalence of use vary enormously depending on the population studied, the methodology of the study, and the definitions of CE used, it is likely that $5 \%-15 \%$ of the US students (the group most studied) have taken CE drugs, ${ }^{1}$ while outside the USA, rates of CE drug use by students are lower. ${ }^{2}$ Use is not limited to students, however. ${ }^{3}$ In order to maintain high cognitive performance, employers may pressure workers to use enhancing substances to counteract fatigue, distress, concentration deficits, or burnout. ${ }^{4} \mathrm{CE}$ drugs are sourced from physicians, ${ }^{5}$ peers, ${ }^{6}$ online pharmacies, ${ }^{7}$ and even criminal groups. ${ }^{8}$

Concerns about CE drug use and particularly the possibility that overall usage may be increasing have made the drugs a focus of attention by academia, ${ }^{9}$ the media, ${ }^{10}$ and even policy makers. ${ }^{11-16}$ Concern has been expressed, not only about the efficacy and safety of substances used, but social attitudes and the ethical, legal, and social implications if usage became widespread.

Though a range of medications have been proffered as cognitive enhancers, in this paper, we will restrict ourselves to the two most frequently cited as having positive
Correspondence: Veljko Dubljević 1955 Rene Levesque Est, S.206 Montreal, QC, H2K 2M4, Canada $\mathrm{Tel}+\mathrm{I} 5 \mid 46237808$

Email veljko.dubljevic@yahoo.com 
cognitive effects in normal individuals - methylphenidate (marketed most commonly as Ritalin or in an extended release form as Concerta) and modafinil (marketed as Provigil in the USA and UK, as Modavigil in Australasia, and as Alertec in Canada). We consider first the mechanism of action and adverse effects of these drugs, then the evidence for their efficacy, before reviewing the debate around advances and societal implications.

\section{The mechanism of action and adverse effects of CE drugs}

Methylphenidate blocks the reuptake of the neurotransmitter dopamine at the synapse. It may also enhance the release of dopamine and noradrenaline (norepinephrine). It is likely, but by no means certain, that any improvement in cognition it may exert is via these routes. ${ }^{17}$

The mechanism of action of modafinil is unknown. ${ }^{18,19}$ It is structurally unrelated to methylphenidate, and evidence suggests that it impacts upon the function of a range of neurotransmitters, including dopamine, noradrenaline, serotonin, glutamate, $\gamma$-aminobutyric acid (GABA), and orexin, though the effect of these changes is uncertain. ${ }^{20}$ One theory is that modafinil may alter the balance of major inhibitory (GABA) and excitatory (glutamate) neurotransmitters, leading to a cascade of neurophysiological events, including the release of both histamine and orexin. ${ }^{18}$ Another is that the stimulation effects of modafinil may be related to its weak dopamine reuptake inhibition and that this amplifies spontaneously released dopamine and noradrenaline. Enhancement of extracellular serotonin levels and serotonin neurotransmission is another possible molecular mechanism of its action. ${ }^{21}$ All in all, the mechanisms underlying modafinil's neuromodulatory effects are complex and somewhat different from older stimulant drugs, such as methylphenidate and amphetamine, potentially incorporating extracellular and intracellular effects. ${ }^{22}$ Furthermore, they seem to focus on hypothalamus-based wakefulness circuits rather than overall brain activation. ${ }^{18}$

Methylphenidate is associated with a range of adverse effects including nervousness, drowsiness, insomnia, and possible adverse effects during pregnancy (See Dubljević ${ }^{23}$ unless otherwise noted, this is the source of information in this paragraph). It may also cause serious cardiovascular adverse events and addiction. The most immediate adverse effect is an increase in blood pressure, which can be dangerous to individuals who suffer from high blood pressure. . $^{24}$ Methylphenidate can be especially dangerous if used in high doses, injected directly into the bloodstream, or inhaled. ${ }^{26}$ When taken orally, methylphenidate enters the body via the intestinal tract and, after a portion has been inactivated by the liver, it enters the general circulation from where it gradually enters the brain across the blood-brain barrier. However, if administered intravenously or inhaled, the drug enters the brain rapidly and without any deactivation, creating the "rush" or "high" - a rapid-onset euphoria.

In contrast to methylphenidate, modafinil seems to pose only modest short-term risks; ${ }^{8}$ however, its relatively recent appearance on the market means that longer term risks may become evident with time. Although modafinil is a weak dopamine reuptake inhibitor, concentrations of the drug achieved after oral dosing are quite high and sufficient to have a substantial action on dopamine reuptake, which might explain the rare occasions of psychosis and mania connected with its use. ${ }^{21,27,28}$ Despite these case reports, the general side effect profile of modafinil is relatively benign, with insomnia, headache, and dizziness being the major problems encountered in trials. ${ }^{29} \mathrm{~A}$ recent review of modafinil overdose suggested that toxic effects were mild in most cases. ${ }^{30}$ Moreover, as modafinil is rarely associated with the rapid effects ("rushes"), euphoric effects ("highs"), or a subsequent decrease in mood and energy ("crashes") seen commonly with amphetamines, it is much less likely to cause addiction, though this cannot by excluded entirely. ${ }^{31,32}$

\section{The efficacy of CE drugs}

Many authors who are interested in direct brain intervention are happy to confidently assert that methylphenidate and modafinil are effective cognitive enhancers. ${ }^{33-36}$ Even when authors do not explicitly state that stimulants improve cognition, they frequently appear to assume that they do. ${ }^{3}$ However, the evidence that either drug might provide any useful form of cognitive enhancement is scant.

The efficacy of methylphenidate and modafinil in neuroenhancement was the topic of a recent, comprehensive, and frequently cited systematic review by Repantis et al. ${ }^{37}$ The authors collated all studies published prior to August 2007 that were single- or double-blind randomized or quasirandomized controlled clinical trials that compared methylphenidate or modafinil with placebo in healthy individuals with reference to effects on attention, memory, and executive function. (The authors also looked at studies examining effects on mood, wakefulness, and motivation, but we have ignored those for the purposes of this paper. Some studies examined these effects on sleep-deprived people, but again we have ignored these, especially as it would be difficult separating out the effect on cognition from the known effect of promoting wakefulness). They found 45 suitable trials 
examining the effects of methylphenidate (20 concerning attention and vigilance, 19 concerning memory and learning, and 6 concerning executive function) and 17 suitable trials examining the effects of modafinil (11 concerning attention and vigilance, 8 concerning memory and learning, and 7 concerning executive function).

The first thing of note concerning these studies is the length of time that the putative cognitive enhancer was taken by subjects. While questions about the efficacy of pharmaceuticals in improving cognition would likely, in most people, conjure notions of people taking the target drug in some sort of ongoing fashion or at least more than once, almost all of the studies are single-dose trials. Of the 45 methylphenidate trials investigating cognition, only 1 involved more than one dose of the drug. This 1973 randomized controlled trial, by Gilbert et al, ${ }^{38}$ enrolled 53 males and females and examined the effect on memory of methylphenidate given twice daily in an increasing regime up to $30 \mathrm{mg}$ a day for 6 weeks. Memory was assessed by the "Guild Memory Test" - a test developed by the lead author - which had not been standardized at the time the trial was published. The researchers found no benefit for methylphenidate over placebo.

Among the 17 modafinil trials investigating cognition, only 1 involved more than one dose and that study involved only two doses - one in the morning and one in the evening of the same day. ${ }^{39}$ This two-dose study, which only included six individuals, was designed to assess the effect of modafinil on persons with low blood sugar, but its design also allowed interpretation of modafinil's effect on normal individuals. It found no beneficial effect of the drug on attention in normal individuals.

The Repantis review, therefore, contained no empirical data to back a claim that either methylphenidate or modafinil would be useful in improving cognition in situations where a person took the drug more than once. All information on efficacy was derived from the following studies that were all single-dose ingestions.

To try to make sense of data from a number of trials, the authors of the Repantis review pooled the data available from any studies that were reported in enough detail to allow extraction of the data on outcome and subjected the data to a meta-analysis. Unfortunately as a number of studies did not allow data extraction, the number of studies available for metaanalysis was considerably reduced. There were only ten studies on the effect of methylphenidate on attention, only four on its effect on memory, and only three on its effect on executive function. The modafinil studies tended to be reported in more detail, allowing 21 studies concerning attention to be subject to meta-analysis, 7 on memory, and 9 on executive function.
With this further analysis, Repantis et $\mathrm{al}^{37}$ found that a single dose of methylphenidate had a very large positive effect on memory and that this finding was highly statistically significant. However, and contrary to popular opinion, the analysis found no statistically significant effect of a single dose of methylphenidate either on attention and vigilance or on executive function. The finding regarding attention was in line with most of the individual studies, most of which reported either no effects, ${ }^{40}$ or sometimes negative effects, such as a disruption of attentional control. ${ }^{41}$

Even the positive finding about improvement in memory is a little difficult to translate into a real world scenario. The type of statistical analysis used was chosen because it allowed markedly different studies to be drawn together, however, the various methods used to assess memory differed markedly from study to study. Most often, subjects were given a list of items to remember and recall or recognize. In other studies, the memory tests used measured changes in visual memory, spatial memory, and working memory. How improved performance on these (often very simple) experimental tasks might translate into real world memory and learning tasks is not clear-especially given the one-dose regime used to induce them.

In contrast to the results for methylphenidate, when Repantis et $\mathrm{al}^{37}$ examined the effects of a single dose of modafinil via meta-analysis, they found no effect on memory, but did find a moderately positive and statistically significant effect on attention and vigilance. There was insufficient data to allow an analysis of modafinil's efficacy in enhancing executive function.

Taken as a whole, and quoting from Repantis et al's review, ${ }^{37}$ "the existing studies provide no consistent evidence for neuroenhancement effects of methylphenidate", though it is clear that a single dose of methylphenidate is able to improve an individual's ability to learn and recall a list of objects, and it is probable that other areas of memory and learning can also be improved. The authors were somewhat more positive about the possible efficacy of modafinil, though their confidence derived mainly from modafinil's assistance in improving the attention of those who are sleep-deprived.

More recent narrative reviews that have relied heavily on the Repantis review, ${ }^{1,2}$ a further systematic review by many of the authors of the Repantis review, ${ }^{42}$ and a small metaanalysis of the effects of modafinil ${ }^{43}$ have all reached similar conclusions. Notably, no study conducted since the Repantis review has used more than one dose of either methylphenidate or modafinil.

While there is some early evidence to suggest that single doses of either methylphenidate or modafinil may offer 
enhancement of some areas of cognitive performance in nonsleep deprived individuals, the findings to date are extremely mixed, and there is no evidence of any sustained effect with more than one dose of either drug. Given the state of the evidence, confident assertions of the utility of these agents as cognitive enhancers seem extremely premature. Nonetheless, a lack of evidence of efficacy is not the same as evidence of a lack of efficacy, and it is possible that these agents may be useful cognitive enhancers. Even if that proves not to be the case, many other putative cognitive enhancers are "in the pipeline", so the investigation of the societal implications of $\mathrm{CE}$ - the focus of the rest of the paper - is timely.

\section{Debate positions and perspectives on CE}

The debate on cognitive enhancement is not new (in this and the following three paragraphs we draw on Dubljević $\left.{ }^{44}\right)$. The issues of sports doping and cosmetic surgery are familiar and frequently discussed. These are the "first-stage" enhancements, and according to Khushf ${ }^{45}$ they had modest effects on society and their harms could be studied and quantified. However, with developments in genetics and neuroscience, and the emergence of the "second-stage" enhancement technologies ${ }^{45}$ the conceptual problem of the boundary between therapy and enhancement has become apparent. There has been a long-standing debate about genetic enhancement, where the potential effects are no longer modest and the harms are potentially devastating. It has produced a number of opposing positions and strategies that have continued to influence the issue of enhancement in general and CE in particular.

On the one hand, there are the "hype and hope" positions associated with transhumanism and posthumanism, which share a utopian belief in the enhanced future of the superhuman race. According to these views, humans could use enhancements to achieve the transition to "posthumans", to create eternal bliss, happiness, and pleasure, to eliminate aging, and greatly enhance our intellectual, physical, and psychological capacities. ${ }^{46} \mathrm{~A}$ notable example is the claim that some of these goals could be achieved by investing in production of the "cheap pill that safely enhances cognition" as a substitute for "years of extra education". ${ }^{47}$ These extremely optimistic metaphysical views, along with the more modest libertarian positions from the debate on genetic enhancement, ${ }^{48}$ continue to shape the broader interests of prominent scientists and researchers.

On the other hand, there are the "gloom and doom" views often tied to religious doctrines and associated with apocalyptic visions of the future. They warn against scientists "playing God" and form the basis of some influential philosophical positions. Some of the most notable in the genetic enhancement debate are those of Fukuyama ${ }^{49}$ and other authors who were members of the US President's Council on Bioethics. ${ }^{11}$ They have set the stage for the entire enhancement debate by focusing on the issue of what it means to be truly human, and what is an authentic human life.

Neuroenhancements in general, and CE in particular, pose new challenges. On the one hand, they are enhancements of the mind, as opposed to the earlier "mindless" enhancements of the body. Also, they concern competent adults making individual choices for themselves, as opposed to the well analyzed question of whether parents have the right to impose irreversible decisions on their unborn children. ${ }^{50,51}$ Moreover, CE promises (or threatens) to challenge and change the lives and work of all citizens, and not just members of certain professions (athletes, movie stars, etc).

The debate positions and policy proposals hinge on the hoped for effects and feared side effects of these agents, as proponents of enhancement are enthusiastically in favor of a smarter society and opponents warn of widespread detrimental social changes (In the rest of this section we draw on Dubljević et $\mathrm{al}^{7}$ ). Accordingly, the debate on cognitive enhancement is, to a large extent, a normative one. Although the questions about the actual properties of existing psychopharmaceuticals are important, along with the questions about prevalence, modalities and reasons for use, the normative issues (eg, should they be used, for what, and by whom) are the most contentious. ${ }^{52}$ By applying different moral theories (consequence based, virtue based, or rights based), different philosophers and neuroethicists come to very different conclusions even when starting from same available factual information. The normative debate on enhancement cannot be resolved solely by empirical data, but the lack of reliable information on current trends and future developments has created a gap that was soon filled with thought experiments and fictional scenarios.

As mentioned above, the normative debate revolves around issues such as authenticity, ${ }^{52}$ human nature, ${ }^{11}$ and utility. ${ }^{53}$ However, one of the most contentious issues is the question of whether CE drug use can be defined as "cheating". Defining a certain practice as cheating can be seen as a social process driven by group interests. These processes are operating continually, and this is likely to lead to alterations in this definition over time. Proponents of enhancement claim that student use of methylphenidate and modafinil is not cheating. Cheating, they claim, is defined as 1) breaking formal or 
informal social norms and 2) attempting to gain an unfair advantage ${ }^{54}$ However, they point out that 1 ) such stimulant drug use is not explicitly banned by all or even the majority of universities and 2) if stimulant drugs were permitted as "study aids", then stimulant use would be an advantage for all. Thus, CE use fits neither criterion for cheating. ${ }^{54}$ Harris $^{54}$ posits an analogy with education and claims that using cognitive enhancement is comparable to seeking out the best schools to improving oneself or one's children. Furthermore, he notes that the costs of stimulant drugs are relatively low, compared to the fees associated with university education or specialized training. He and other proponents contend that we should use any means of improvement as long as they are effective and, by using examples such as aspirin, literacy, electricity, coffee, and computers, conclude that evolution and progress are synonymous with enhancement. ${ }^{53,54}$

Authors skeptical toward the claims of proponents of enhancement have a markedly different view of the matter. ${ }^{55}$ Some critics ${ }^{44}$ start from the premise that rules are put in place when new practices of cheating are discovered and draw on influential theories of justice, such as that of Rawls, ${ }^{56}$ to make the case that using cognitive enhancement is unfair. According to this argument, therapeutic uses of drugs that might improve cognition, in the case of citizens suffering from attention deficit hyperactivity disorder (ADHD) or narcolepsy represent the provision of basic necessities for those who are lacking, benefiting the least advantaged or restoring citizens to a position of equal opportunity and liberty. On the other hand, using drugs for cognitive enhancement without clear medical need does none of this. ${ }^{44}$ This line of argument is recognized even by authors trying to stake out the middle ground between opponents and proponents of cognitive enhancement. A prominent position in this regard is that cognitive enhancement has more potential to increase factual inequalities between members of society than decrease or ameliorate them. ${ }^{57}$

Dubljevićs ${ }^{58}$ goes further to claim that cognitive enhancements are currently being used as means for obtaining undeserved positional advantage. Under this view, if students use methylphenidate during an exam because they are diagnosed with ADHD they are merely availing themselves of a fair opportunity to compete with other students on an equal footing. However, if they use it as enhancement, even assuming it is effective, they are taking a chance with the unknown long-term side effects in order to gain advantage over others. Others have noted that cognitive enhancers could affect the competition between those who would prefer using them and those who would rather not, ${ }^{3}$ creating an incentive, or even a pressure, among nonusers to start using too. ${ }^{59,60}$ This could lead to a situation in which all students need, or believe that they need, to use cognitive enhancers to be able to compete.

Similarly, employees in different lines of work might need, or believe that they need, to use cognitive enhancers to hold on to their jobs. ${ }^{4}$ Employers might coerce them (even indirectly) in order to maximize profit. In this scenario, employees would bear the risks of long-term effects without any realistic opportunity to refuse to do so. ${ }^{58}$ In the long run, competitive pressures and contagion might start affecting the basic structure of society, leading to an ever-increasing number of cognitive enhancement users.

From the point of view of the critics, the unfairness of cognitive enhancement calls for the introduction of rules and/ or justifies the implicit or explicit norms that are in place. So, the opponents of enhancement argue there should be rules that, at least, discourage the use of stimulant drugs as a matter of justice, ${ }^{44,58}$ and claim that most people intuitively share a similar position (refer the discussion on public attitudes on cognitive enhancement in "Social aspects of CE use" section). However, in his analysis of cognitive enhancement and justice, Savulescu ${ }^{61}$ reaches a drastically different conclusion: justice requires enhancement. According to Savulescu, ${ }^{61}$ nature allots advantages and disadvantages with no regard to fairness. Since enhancement might improve people's lives, the social distribution of cognitive enhancers should be designed to make sure that everyone, regardless of natural inequality, has a decent chance of a decent life. ${ }^{61}$

The question of whether the least advantaged could benefit or be harmed by cognitive enhancers is an empirical one that could be resolved with new insights into the physiological and social effects. On the normative side, however, with the advent of competing theories of justice, ${ }^{62-65}$ the issue is not likely to be resolved in a single stroke.

\section{Social aspects of CE use}

CE drugs have the potential to create social problems beyond boundaries of a single society (In this and the following three paragraphs we draw on Dubljevićc6 ${ }^{6}$. Societies do not implement public policies in a vacuum, but are bound to a certain extent by various international conventions and treaties. The 1971 United Nations Convention on Psychotropic Drugs ${ }^{67}$ provides an example as it explicitly lays out the regulatory framework for two substances commonly encountered in the literature on cognitive enhancement - amphetamine and methylphenidate. ${ }^{23}$ The designers of the Convention were motivated by the knowledge that the drugs could 
cause serious harm and even major international incidents. Notably though, the Convention is silent on newer drugs, such as modafinil, and therefore no international framework for their regulation is in place. In contrast to the older drugs, the regulation of modafinil seems to be relatively unclear in international comparison, as it differs significantly from country to country. ${ }^{8}$

As noted above, the empirical evidence on prevalence of $\mathrm{CE}$ use is ambiguous, and estimates range from $1.5 \%$ in the general population in Germany to as high as $35 \%$ of the student population in certain colleges in the USA. ${ }^{2}$ Comparisons of prevalence rates are difficult due to differences in study designs and populations sampled (For more detailed discussions concerning available information on prevalence rates in different countries around the world see Jotterand and Dubljević ${ }^{68}$ and the chapters contained therein). While detailed and reliable information on the prevalence of $\mathrm{CE}$ is still mostly lacking, the media-hype seems to exaggerate the popularity of CE. ${ }^{69}$ This media attention might raise the awareness that such drugs exist, along with providing inaccurate information regarding the effects and side effects, thus increasing their use. ${ }^{70}$

There is also a lack of evidence around the social attitudes toward cognitive enhancement, however, those studies that have been done suggest that the majority of people seem to regard the use of CE as unfair. ${ }^{71}$ In one Australian study, for example, $85 \%$ of the sample of the general population believed that the use of medications for cognitive enhancement was morally unacceptable. ${ }^{72}$ This is similar to findings in other surveys conducted in other countries and populations. ${ }^{2,7,73}$ University students also typically regard the use of cognitive enhancers as unfair. ${ }^{74}$ However, mirroring the academic debate on the issue, a steady minority of respondents in the student and general population surveys report that use of cognitive enhancers is both acceptable and fair. ${ }^{75}$ These differences in attitudes might be linked with differences in information about, and interpretation of, adverse effects and/or differences in the context of use. It may be that some people think that adverse effects of cognitive enhancers are minor and as such acceptable, whereas the majority is perhaps more risk averse, choosing to avoid and impose sanctions against the use of CE in the absence of scientific evidence concerning long-term safety.

The difference between competitive and cooperative contexts (especially in the examples used in academic treatises) might be the relevant feature that guides normative evaluation. ${ }^{71}$ The fact that some students view cognitive enhancement as cheating and some do not could be related to the different interpretation of the character of university education - whether it is understood as being dominantly competitive (or a zero-sum game) or cooperative (and nonzero-sum). This explanation is in line with the findings from a US based study that enhancement of physical functions in sports is viewed as more problematic than enhancement of cognitive capacity in the university context. ${ }^{73}$ Sports are more related to zero-sum expectations than university education. The authors of this study conclude that their results support the use of promotional activities designed to establish cognitive enhancement use as cheating in educational contexts. ${ }^{73}$ However, promotional activities of this sort might be counterproductive. If, as hypothesized, cognitive enhancement drug use is viewed as cheating in competitive contexts but is not so viewed in cooperative contexts, a clarification of context in future empirical studies might provide less ambiguous data on public attitudes on cognitive enhancement.

Thus, future studies might be improved if they check for the context of use of cognitive enhancers as the possible issue framing the normative valence of different responses. Consider the question of measuring performance: it could be argued that cognitive enhancement use might counteract the aim of tests, eg, in cases where the students' memorization is tested but students have used memory enhancers. ${ }^{76}$ This problem is similar to the illicit use of calculators (something that is in itself not problematic) when mental arithmetic should be tested.

\section{Conclusion}

As things stand, there is little evidence that either methylphenidate or modafinil are likely to provide any useful cognitive enhancement to those who choose to use them. However, it is possible that further research may reveal they do offer cognitive benefit or, perhaps more likely, future research into other agents, not yet available, may offer the development of proven "smart drugs".

The proponents of enhancement insist that methylphenidate and modafinil or any future smart drugs are in essence similar to old and familiar cognitive enhancers like coffee and tea. They then base their argument on the appeal to the fairness of treating like cases alike. Nevertheless, policy options in a democratic society are not limited to laissez-faire as argued for by most proenhancement authors, or to the strictest form of prohibition as opponents would like. There are also options of regulation so that the individual use is encouraged (eg, via government incentives) or discouraged (eg, via taxation), or even to make the use mandatory. ${ }^{77}$ The point is that fairness of treating like cases alike depends on 
defining sufficiently like cases, and that can only be done by drawing on empirical findings on known effects..$^{23,44,58,60,66}$

Policy makers in the USA and European Union (EU) have deemed questions regarding the regulation of cognitive enhancement important, and several studies and reports have been completed on their behalf. ${ }^{11-16}$ These documents offered analyses of the distinction between therapy and enhancement, and very often cite fictional scenarios about the impact of possible, future technologies. Whatever the merits or faults of these reports, the use of CE drugs for nonmedical purposes by healthy adults is currently still not (adequately) regulated in the EU and USA. ${ }^{34}$

Finally, even if the current legal regime does not adequately address the social phenomenon of CE use, it has to be noted that the legal status for the nonmedical use of methylphenidate is clear and unified across the globe. Namely, the United Nations Convention on Psychotropic Substances ${ }^{67}$ defines schedules for potentially dangerous psychotropic substances and explicitly lists methylphenidate as a Schedule II drug (which lists controlled substances with known medical uses). All countries that have ratified this Convention are obligated to regulate methylphenidate accordingly. Thus, the legal sanctions related to "study aid" use, depending on jurisdiction, might include even liability to imprisonment if methylphenidate is sold to or shared with others. Modafinil did not exist at the time the international legal framework was established and is not mentioned in Convention's schedules. Partly as a consequence of this, the controls around modafinil vary enormously from country to country.

\section{Disclosure}

The authors report no conflicts of interest in this work.

\section{References}

1. Smith ME, Farah MJ. Are prescription stimulants "smart pills?" The epidemiology and cognitive neuroscience of prescription stimulant use by normal healthy individuals. Psychol Bull. 2011;137(5):717-741.

2. Ragan CI, Bard I, Singh I. What should we do about student use of cognitive enhancers? An analysis of current evidence. Neuropharmacology. 2013;64:588-595.

3. Sahakian B, Morein-Zamir S. Professor's little helper. Nature. 2007; 450(20):1157-1159.

4. Appel JM. When the boss turns pusher: a proposal for employee protections in the age of cosmetic neurology. J Med Ethics. 2008;34: 616-618.

5. Larriviere D, Williams MA, Rizzo M, Bonnie RJ. Responding to requests from adult patients for neuroenhancements. Guidance of the Ethics, Law and Humanities Committee. Neurology. 2009;73:1406-1412.

6. DeSantis AD, Webb EM, Naor SW. Illicit use of prescription ADHD medications on a college campus: a multimethodological approach. J Am Coll Health. 2008;57(3):315-323.

7. Dubljević V, Sattler S, Racine E. Cognitive enhancement and academic misconduct: a study exploring their frequency and relationship. Ethics Behav. 2013;24(5):408-420.
8. Dubljević V. Enhancement with modafinil: benefiting for harming the society? In: Jotterand F, Dubljević V, editors. Cogntive Enhancement: Ethical and Policy Implications in International Perspectives. Oxford, UK: Oxford University Press; 2015. In press.

9. Dubljevic V. Response to open peer commentaries on "prohibition or coffee shops: regulation of amphetamine and methylphenidate for enhancement use by healthy adults." Am J Bioethics. 2014;14(1): $\mathrm{W} 1-\mathrm{W} 8$.

10. Dubljević V, Saigle V, Racine E. The rising tide of tDCS in the media and academic literature. Neuron. 2014;82(4):731-736.

11. US President's Council on Bioethics. Beyond Therapy: Biotechnology and the Pursuit of Happiness. Washington, DC: US President's Council on Bioethics; 2003.

12. European Group on Ethics in Sciences and New Technologies. Opinion on the Ethical Aspects of ICT Implants in the Human Body: Opinion of the European Group on Ethics in Sciences and New Technologies to the European Commission. Vol 20. Luxembourg: Office for Official Publications of the European Communities; 2005.

13. British Medical Association. Boosting Your Brainpower: Ethical Aspects of Cognitive Enhancements. A Discussion Paper from the British Medical Association [BMA]; 2007. Available from: http://enhancingresponsibility.com/wp-content/uploads/2014/01/ Boosting_brainpower_tcm41-147266.pdf. Accessed June 22, 2015.

14. Frauenhofer Institute. Converging Technologies and their Impact on the Social Sciences and Humanities; 2008. Available from: http://ethics. iit.edu/NanoEthicsBank/node/1843. Accessed June 22, 2015.

15. JASON Advisory Group. Human Performance. JASON (Program for Office of Defense Research and Engineering) (No JSR-07-625). JASON Advisory Group for Department of Defence, Pentagon; 2008. Available from: http://www.fas.org/irp/agency/dod/jason/human.pdf. Accessed June 22, 2015.

16. Science and Technology Options Assessment (STOA). Human Enhancement Study. The Hague, the Netherlands: Rathenau Institute; 2009.

17. Sulzer D, Sonders MS, Poulsen NW, Galli A. Mechanisms of neurotransmitter release by amphetamines: a review. Prog Neurobiol. 2005;75(6):406-433.

18. Ballon JS, Feifel D. Systematic review of modafinil: potential clinical uses and mechanisms of action. J Clin Psychiatry. 2006;67(4):554-566.

19. de Jongh R, Bolt I, Schermer M, Olivier B. Botox for the brain: enhancement of cognition, mood and pro-social behavior and blunting of unwanted memories. Neurosci Biobehav Rev. 2008;32(4):760-776.

20. Minzenberg MJ, Carter CS. Modafinil: a review of neurochemical actions and effects on cognition. Neuropsychopharmacology. 2008;33(7):1477-1502.

21. Kanal M, Ozkan C, Doganavsargil O, Eryilmaz M. Late onset mania due to modafinil use: a case report. Bull Clin Psychopharmacol. 2012;22(1):71-74

22. Gerrard P, Malcolm R. Mechanisms of modafinil: a review of current research. Neuropsychiatr Dis Treat. 2007;3(3):349-364.

23. Dubljević V. Prohibition or coffee-shops: regulation of amphetamine and methylphenidate for enhancement use by healthy adults. $\mathrm{Am} J$ Bioethics. 2013;13(7):23-33.

24. Iversen L. Speed, Ecstasy, Ritalin. The Science of Amphetamines. London, UK: Oxford University Press; 2008.

25. Hysek CM, Simmler LD, Schillinger N, et al. Pharmacokinetic and pharmacodynamic effects of methylphenidate and MDMA administered alone and in combination. Int $J$ Neuropsychopharmacol. 2014; 17:371-381.

26. Bruggisser M, Bodmer M, Liechti ME. Severe toxicity due to injected but not oral or nasal abuse of methylphenidate tablets. Swiss Med Wkly. 2011;141:w13267.

27. Mariani JJ, Hart CL. Psychosis associated with modafinil and shift work. Am J Psychiatry. 2005;162(10):1983.

28. Wu P, Jones SG, Ryan CJ, Michail D, Robinson T. Modafinil-induced psychosis. Intern Med J. 2008;38(8):677-678. 
29. Sheng P, Hou L, Wang X, et al. Efficacy of modafinil on fatigue and excessive daytime sleepiness associated with neurological disorders: a systemic review and meta-analysis. PLoS One. 2013;8(12):e81802.

30. Carstairs SD, Urquhart A, Hoffman J, Clark RF, Cantrell FL. A retrospective review of supratherapeutic modafinil exposures. J Med Toxicol. 2010;6(3):307-310.

31. Mohamed AD. Modafinil has the potential for addiction. AJOB Neurosci. 2012;3(2):36-38.

32. Volkow ND, Fowler JS, Logan J, et al. Effects of modafinil on dopamine and dopamine transporters in the male human brain. Clinical implications. J Am Med Assoc. 2009;301(11):1148-1154.

33. Anonymous. Cognitive enhancement. All on the mind. The Economist. May 22, 2008

34. Greely H, Sahakian B, Harris J, et al. Towards responsible use of cognitiveenhancing drugs by the healthy. Nature. 2008;456(11):702-705.

35. Greely HT. Law and the revolution in neuroscience: an early look at the field. Akron Law Rev. 2009;42:687-715.

36. Mohamed AD, Sahakian BJ. The ethics of elective psychopharmacology. Int J Neuropsychopharmacol. 2011;15:559-571.

37. Repantis D, Schlattmann P, Laisney O, Heuser I. Modafinil and methylphenidate for neuroenhancement in healthy individuals: a systematic review. Pharmacol Res. 2010;62:187-206.

38. Gilbert JG, Zimmer LE, Kubis JF, Donnelly KJ. Effect of magnesium pemoline and methylphenidate on memory improvement and mood in normal aging subjects. Int J Aging Human Dev. 1973;4(1):35-51.

39. Smith D, Pernet A, Rosenthal JM, et al. The effect of modafinil on counter-regulatory and cognitive responses to hypoglycaemia. Diabetologia. 2004;47(10):1704-1711.

40. Turner DC, Robbins TW, Clark L, Aron AR, Dowson J, Sahakian BJ. Relative lack of cognitive effects of methylphenidate in elderly male volunteers. Psychopharmacology. 2003;168(4):455-464.

41. Rogers RD, Blackshaw AJ, Middleton HC, et al. Tryptophan depletion impairs stimulus-reward learning while methylphenidate disrupts attentional control in healthy young adults: implications for the monoaminergic basis of impulsive behaviour. Psychopharmacology. 1999; 146:482-491.

42. Fond G, Micoulaud-Franchi JA, Macgregor A, et al. Neuroenhancement in healthy adults, part I: pharmaceutical cognitive enhancement: a systematic review. J Clin Res Bioethics. 2015;6(2):1000213.

43. Kelley AM, Webb CM, Athy JR, Ley S, Gaydos S. Cogntion enhancement by modafinil: a meta-analysis. Aviat Space Environ Med. 2012;83: 685-690.

44. Dubljević V. Principles of justice as the basis for public policy on psycho-pharmacological cognitive enhancement. Law Innov Technol. 2012;4(1):67-83.

45. Khushf G. The use of emergent technologies for enhancing human performance: are we prepared to address the ethical and policy issues? Publ Pol Pract. 2005;4(2):1-17.

46. Campa R. Pure science and the posthuman future. J Evol Technol. 2008;19(1):28-34.

47. Bostrom N. Smart policy: cognitive enhancement in the public interest. In: Zonneveld L, Dijstelbloem H, Ringoir D, editors. Reshaping the Human Condition: Exploring Human Enhancement. The Hague, the Netherlands: Rathenau Institute; 2008:29-36.

48. Agar N. Liberal Eugenics: In Defense of Human Enhancement. Malden, MA: Wiley-Blackwell; 2005.

49. Fukuyama F. Our Posthuman Future: Consequences of the Biotechnology Revolution. New York, NY: Picador; 2002.

50. Habermas J. Die Zukunft der menschlichen Natur [Future of Human Nature]. Frankfurt am Main, Germany: Suhrkamp; 2001.

51. Buchanan A, Brock D, Daniels N, Wikler D. From Chance to Choice: Genetics and Justice. Cambridge, UK: Cambridge University Press; 2000.

52. Parens E. Authenticity and ambivalence: toward understanding the enhancement debate. Hastings Cent Rep. 2005;35(3):34-41.
53. Levy N. Neuroethics. Cambridge, UK: Cambridge University Press; 2007.

54. Harris J. Chemical cognitive enhancement: is it unfair, unjust, discriminatory, or cheating for healthy adults to use smart drugs? In: Illes J, Sahakian B, editors. Oxford Handbook of Neuroethics. Oxford, UK: Oxford University Press; 2011:265-272.

55. Selgelid M. An argument against arguments for enhancement. Stud Ethics Law Technol. 2007;1(1) Art. 12.

56. Rawls J. A Theory of Justice - Revised Edition. Cambridge, MA: Harvard University Press; 1999.

57. Glannon W. Psychopharmacological enhancement. Neuroethics. 2008;1(1):45-54.

58. Dubljević V. Toward a legitimate public policy on cognition-enhancement drugs. Am J Bioethics Neurosci. 2012;3(3):29-33.

59. Forlini C, Racine E. Autonomy and coercion in academic "cognitive enhancement" using methylphenidate: perspectives of key stakeholders. Neuroethics. 2009;2(3):163-177.

60. Dubljević V. Cognitive enhancement, rational choice and justification. Neuroethics. 2013;6(1):179-187.

61. Savulescu J. Justice, fairness and enhancement. Ann N Y Acad Sci. 2006;1093:321-338.

62. Nozick R. Anarchy, State, and Utopia. New York, NY: Basic Books; 1974.

63. Miller D. Principles of Social Justice. Cambridge, MA: Harvard University Press; 1999.

64. Sen A. The Idea of Justice. Cambridge, MA: Belknap Press of Harvard University Press; 2009.

65. Walzer M. Spheres of Justice. New York, NY: Basic Books; 1983.

66. Dubljević V. Cognitive enhancement: a glance at the future and ethical considerations. In: Knafo S, Venero C, editors. Cognitive Enhancement, Amsterdam, the Netherlands: Elsevier; 2015:343-365.

67. United Nations. Convention on Psychotropic Substances, 1971. Available from: http://www.unodc.org/unodc/en/treaties/psychotropics. html. Accessed June 22, 2015.

68. Jotterand F, Dubljević V, editors. Cognitive Enhancement: Ethical and Policy Implications in International Perspectives. Oxford, UK: Oxford University Press. 2015 In Press.

69. Kolker R. The real limitless drug isn't just for lifehackers anymore. New York Magazine. March 31, 2013. Available from: http://nymag. com/news/intelligencer/modafinil-2013-4/. Accessed April 2, 2013.

70. DAK. Gesundheitsreport 2009. Analyse der Arbeitsunfähigkeitsdaten. Schwerpunkthema Doping am Arbeitsplatz [Healthreport 2009. Analysis of Workforcedata. Focus topic Doping in the Workplace]. Berlin, Germany: IGES; 2009.

71. Schelle KJ, Faulmuller N, Caviola L, Hewstone M. Attitudes toward pharmacological cognitive enhancement - a review. Front Syst Neurosci. 2014;8:53.

72. Partridge B, Lucke J, Hall W. A comparison of attitudes toward cognitive enhancement and legalized doping in sport in a community sample of Australian adults. Am J Bioethics Prim Res. 2012;3(4):81-86.

73. Dodge T, Williams KJ, Marzell M, Turrisi R. Judging cheaters: is substance misuse viewed similarly in the athletic and academic domains? Psychol Addict Behav. 2012;26(3):678-682.

74. Bell S, Partridge B, Lucke J, Hall W. Australian university students' attitudes towards the acceptability and regulation of pharmaceuticals to improve academic performance. Neuroethics. 2013;6(1):197-205.

75. Fitz NS, Nadler R, Manogaran P, Chong EWJ, Reiner P. Public attitudes toward cognitive enhancement. Neuroethics. 2013;7(2):173-188.

76. Schermer M. On the argument that enhancement is "cheating". J Med Ethics. 2008;34(2):85-88

77. Blank R. Globalization: pluralist concerns and contexts. In: Giordano J, Gordijn B, editors. Scientific and Philosophical Perspectives in Neuroethics. Cambridge, UK: Cambridge University Press; 2010: 321-342. 
Neuroscience and Neuroeconomics

\section{Publish your work in this journal}

Neuroscience and Neuroeconomics is an international, peer-reviewed, open access journal focusing on the identification of brain structures and measurement of neural activity related to behavior, behavioral predictions, and decision making in health and disease. The manuscript
Dovepress

management system is completely online and includes a very quick and fair peer-review system. Visit http://www.dovepress.com/testimonials. php to read real quotes from published authors.

Submit your manuscript here: http://www.dovepress.com/neuroscience-and-neuroeconomics-journal 